\title{
A natural laboratory for small estuary studies: the reincarnation of Town Pond
}

\author{
S. Mecca ${ }^{1}$, M. Oumano ${ }^{1}$, R. LaMontagne ${ }^{1} \&$ D. Johnson ${ }^{2}$ \\ ${ }^{I}$ Department of Engineering-Physics-Systems, Providence College, USA \\ ${ }^{2}$ Rhode Island Nuclear Science Center, USA
}

\begin{abstract}
Early maps document a 70 acre salt marsh encased estuary that during the 1950s was filled with dredge spoils by the U.S. Army Corps of Engineers. A number of stakeholders including Save the Bay, a non-profit advocacy group supported a restoration of this ecosystem and in 2006, the Corps of Engineers completed the restoration project. The resulting system offers a unique opportunity to observe the early evolution of a new estuarian ecosystem and provides a natural laboratory for short and long-term studies of the dynamics of small estuaries. This paper briefly overviews the stages leading to the present system, offers a set of experiments that will aid in creating a baseline for future studies and describes progress on a sediment survey currently underway.
\end{abstract}

Keywords: tidal embayment, estuary dynamics, sediment analysis.

\section{The life and rebirth of Town Pond}

Town Pond, also known as Boyd's Lane Marsh for the roadway of the same name that abutted the original salt basin, was a 60-80 acre site located at lat lon, $41^{\circ} 38^{\prime}-7^{\circ} 14^{\prime}$, at the northern tip of Aquidneck Island in the town of Portsmouth, Rhode Island USA. The segment of an early map documenting a 1938-39 survey revised ten years later [1] is shown in Figure 1. The map depicts a few important features. First and most obvious is a body of water with an inlet from Mt Hope Bay in the upper area of Narragansett Bay. The map also depicts a vegetative marsh surrounding the embayment and a brook feeding the basin from its south end. A railroad bridge is also seen in this map segment at the upper, marine end, of the basin. 


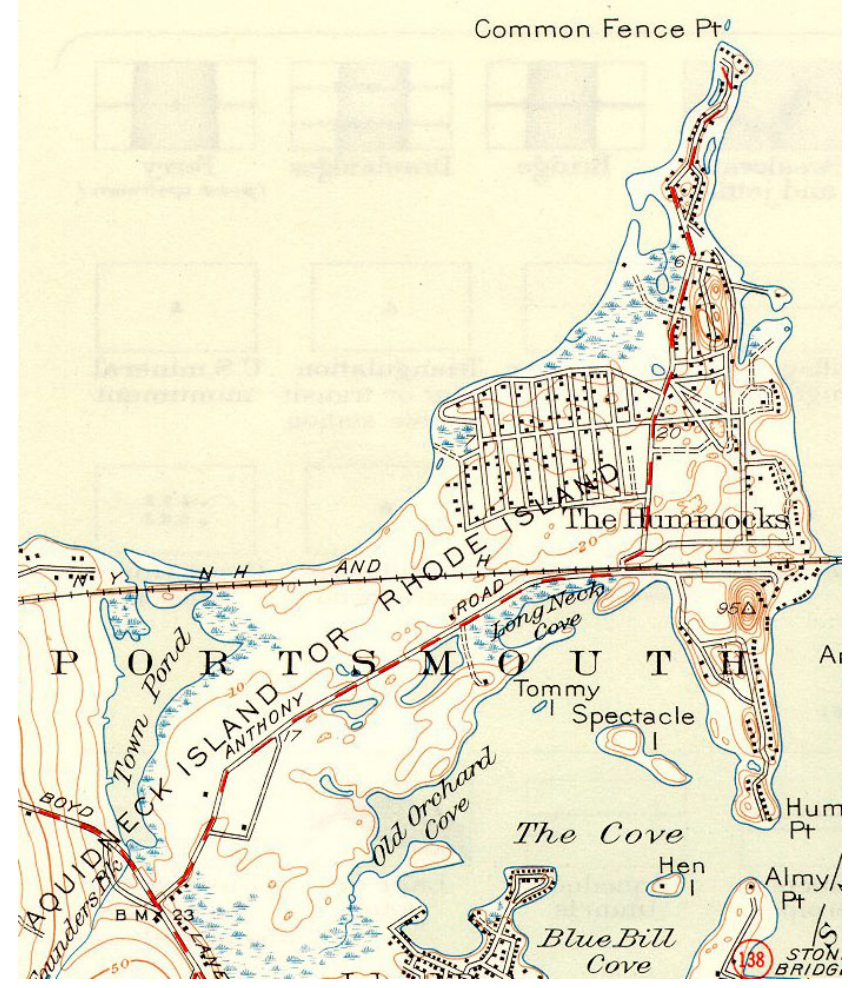

Figure 1: $\quad$ An early map of Town Pond [1].

During the mid 1950s the US Army Corps of Engineers (ACOE) deposited dredge spoils from operations in Mt Hope Bay into Town Pond. This raised the elevation of the estuary gradually resulting in the habitat becoming invaded with Phragmites australis and reducing the volume and surface area of salt water accumulation in the system.

Following years of advocacy a partnership, that included the AOCE the RI Department of Environmental Management (RIDEM), the US Environmental Protection Agency, RI Coastal Resources Management Council, Roger Williams University, Aquidneck Land Trust, RI Department of Transportation, Corporate Wetlands Restoration Partnership, Ducks Unlimited, Town of Partmouth and the Narragansett Bay Estuary Program, succeeded in planning and completing a \$4.6 million restoration of Town Pond as a functioning estuary. On September 21, 2007 after 50 years of deadly decline, water from Mt Hope Bay flowed into the reincarnated Town Pond.

Figure 2 shows a Google Earth pre-construction view of Town Pond and Figure 3 an overlay of the historic map [1] with a wider view of the Google Earth image.

The spatial extent of the original basin (overlay) is clear on the underlay Google Earth image. 


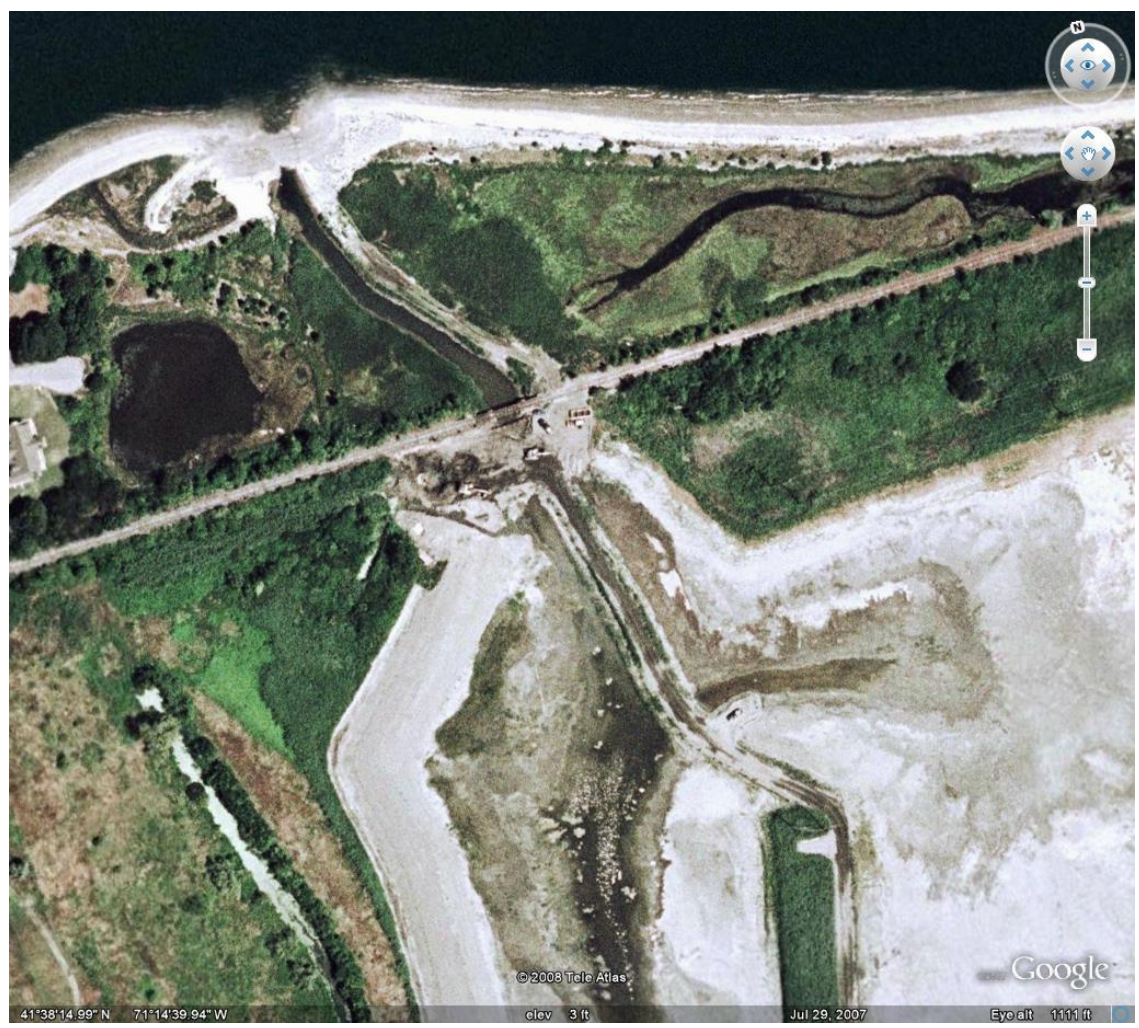

Figure 2: $\quad$ Pre-restoration view of Town Pond from Google Earth.

\section{Structure of the new system}

Figure 4 shows the re-construction plans for Town Pond including the relevant elevations. According to a June 16, 2008 RIDEM release [3], it was estimated that some 125,000 cubic yards of deposited dredge spoils were excavated creating elevations appropriate for " 2.5 acres of high marsh, 8.9 acres of low marsh, 3.2 acres of mudflats and 8.2 acres of permanent open water. A weir with a top elevation of -0.2 feet NGVD will maintain permanent open water depths between 1.8 and 2.9 feet." The west side of the basin has an earth berm and, coupled with a 42" flap valve, shown in Figure 5, to admit fresh water from Founder's Brook, this creates a somewhat controlled supply of fresh water to the basin.

Figure 6 offers an aerial view of the site taken on August 16, 2008 about $1 \mathrm{hr}$ 20 minutes after low tide. The photo shows the extent of the renovated basin including the marine and estuary regions as well as the landscape surrounding the renovated site. Founder's Brook is highlighted to emphasize its location and the earth berm running more or less parallel to the brook can be seen to the east. 


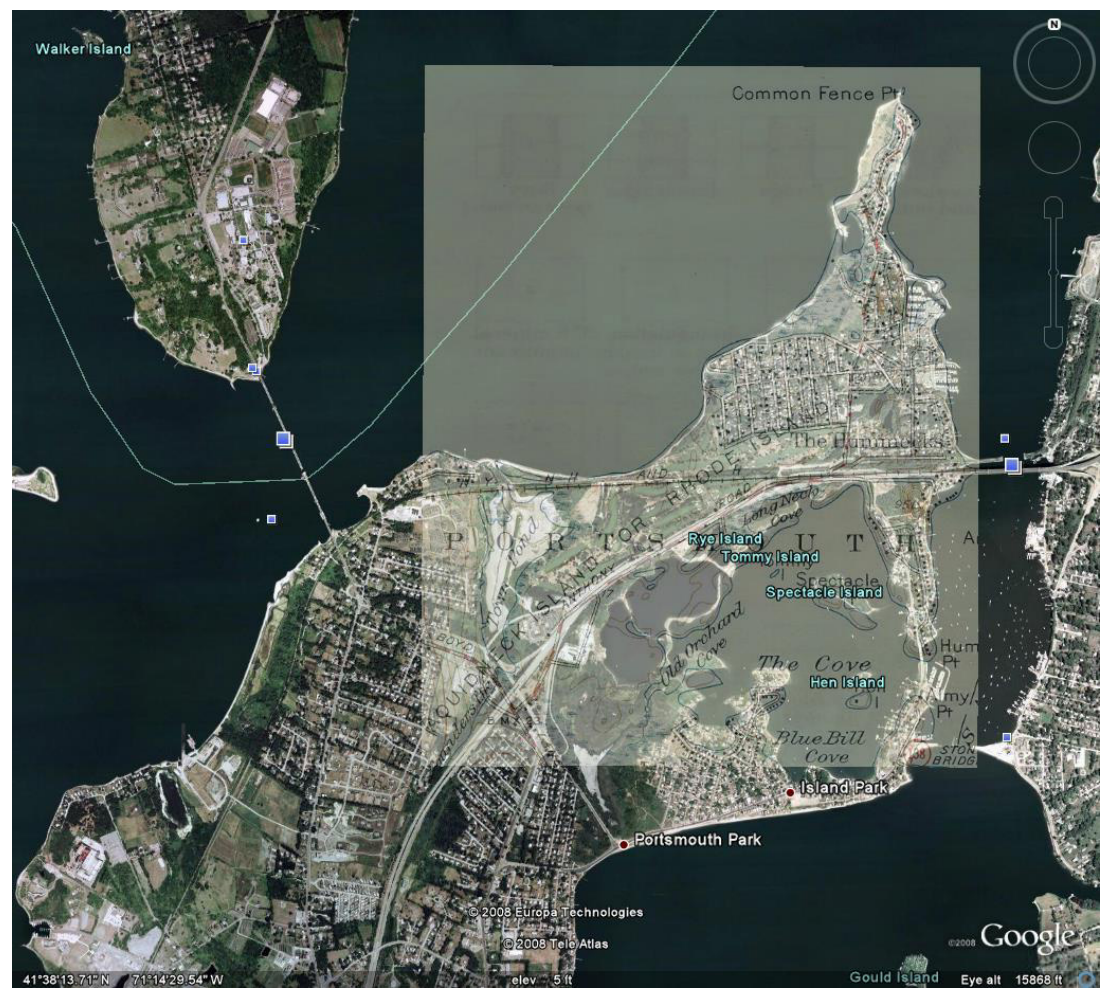

Figure 3: Historical map segment overlayed on Google Earth pre-restoration image.

\section{A natural laboratory}

The aforementioned berm, redirected lower reaches of Founder's Brook and the flap valve, while creating a dynamically different Town Pond than what is seen in the historical maps, nevertheless offers a natural living laboratory for the conduct of investigations of both physical processes as well as fish-, wildlifeand habitat- dynamics. Indeed, the berm limits direct fresh water runoff into Town Pond; in addition to rainfall and pond environs drainage, the major source of fresh water to the basin is from the brook and from runoff that accumulates on the west side of the berm and enters through the valve. Some of the experiments and studies currently underway in our laboratory include:

- An analysis of sediments taken from 28 locations in the marine- freshand estuary zones;

- A water balance analysis of the estuary including precipitation, evaporation, fresh water and salt water exchanges from tidal dynamics;

- Transverse and longitudinal salinity gradient studies;

- Analysis of the aforementioned hindsight pre-restoration data;

- Extension of the MSB model [3-6] to estuarian systems and calibration of the model to Town Pond. 


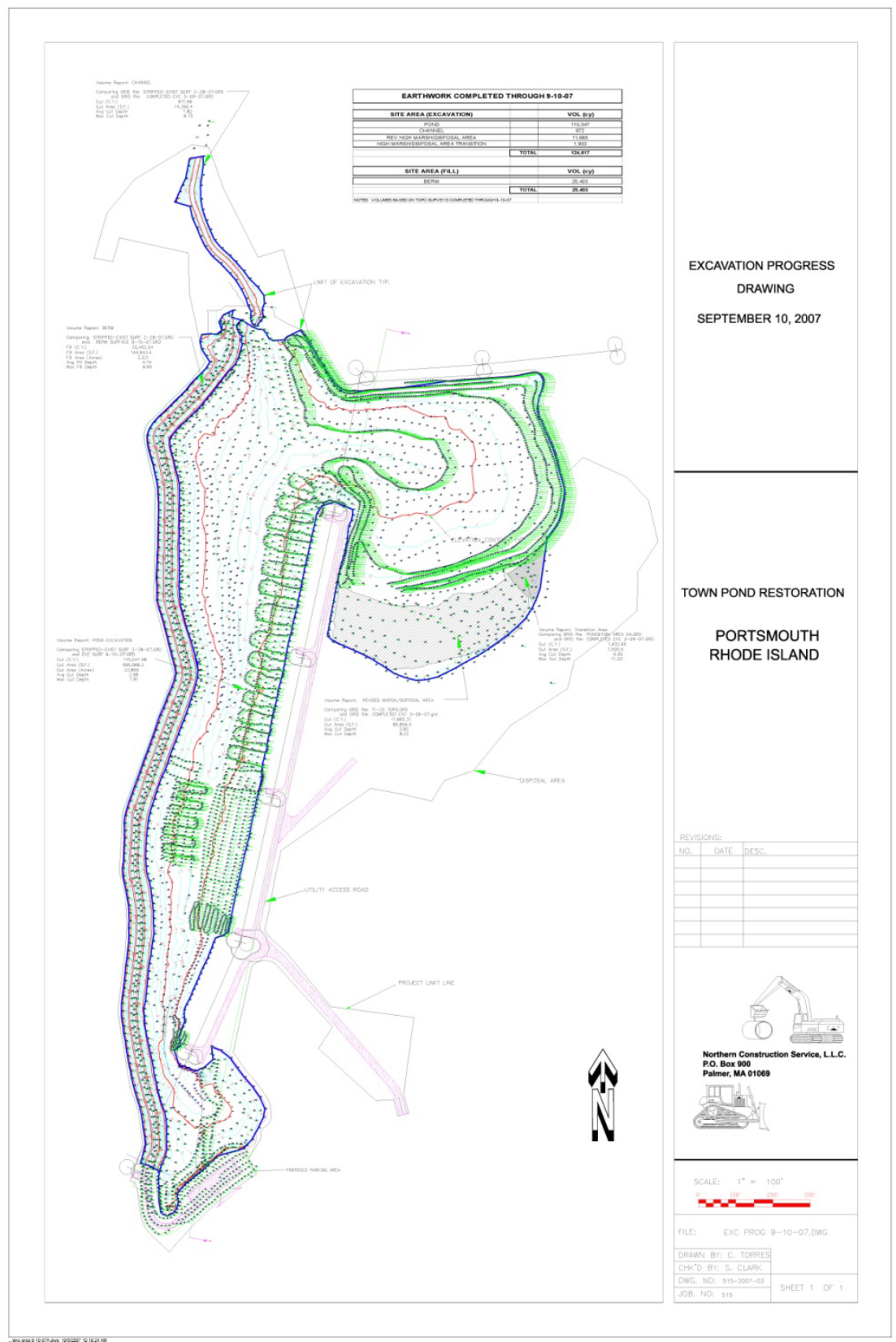

Figure 4: Excavation drawing September 10, 2007. Reprinted with permission. 
178 River Basin Management V

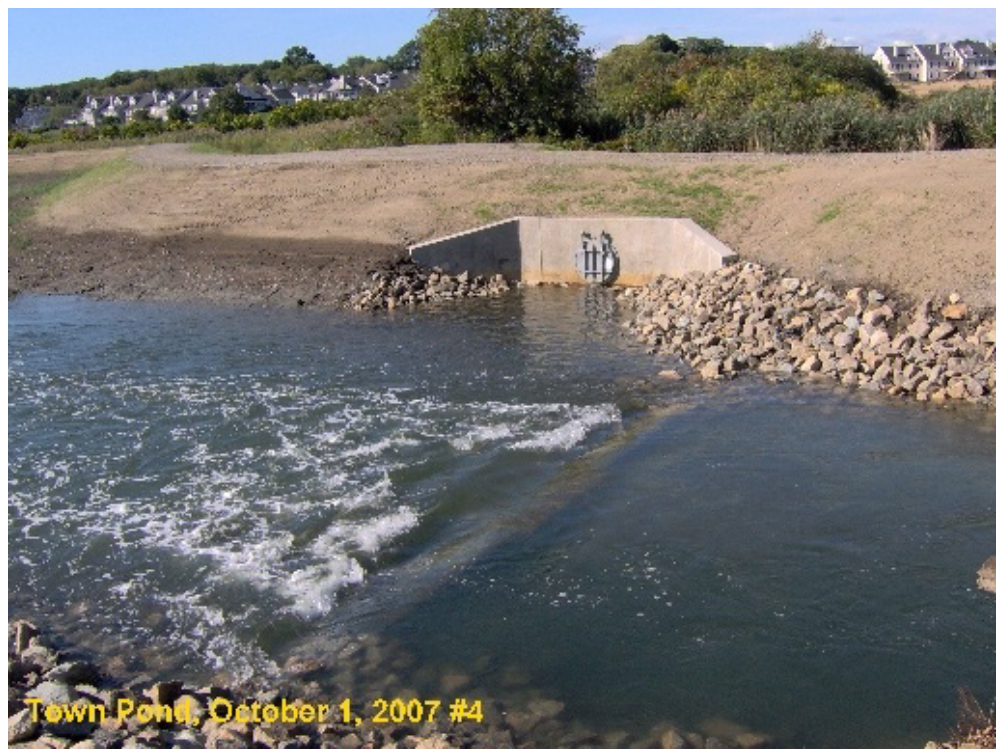

Figure 5: $\quad$ Photograph of the flap valve and weir.

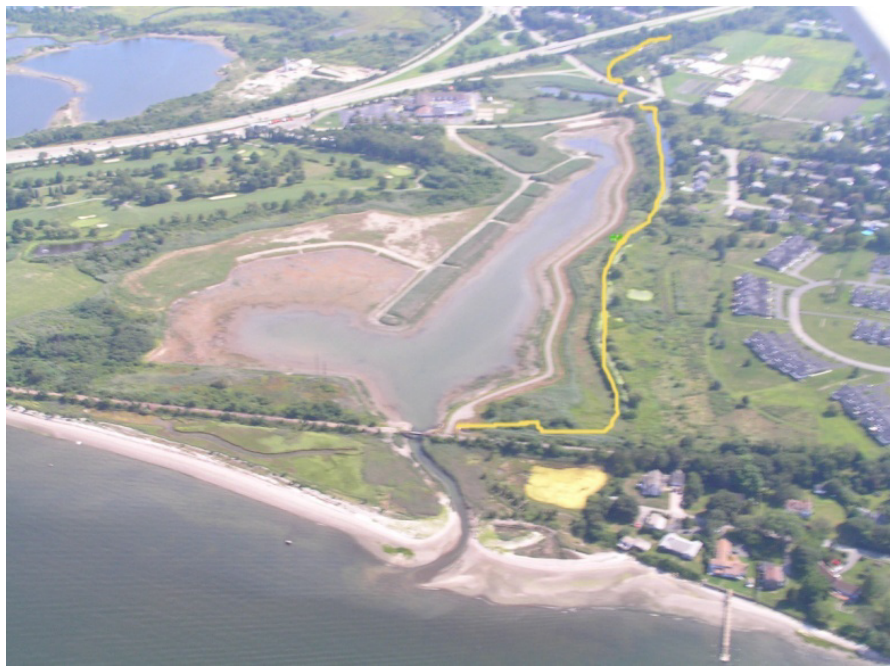

Figure 6: Aerial view of the renovated site with Founder's Brook highlighted.

It is important that baseline data be established now to give relevance to future observations and studies. 
Water height, temperature and salinity data on the pre-restoration system the railroad bridge was acquired over a period of 10 years by a retired engineer (see acknowledgements); and this data. The extent of the tiny basin is not well known and any analysis of this hindsight data will require significant assumptions on spatial and flow parameters, factors that are still being investigated.

\section{Sediment preparation and analysis}

Sediment samples were taken from 28 points shown in Figure 7. A homemade pneumatic device was used to extract samples from the upper $3-5 \mathrm{~cm}$ of the sediment. Simultaneously, surface salinity, depth and time of measurement were also measured as part of a separate survey. Sediments were prepared by drying for 5 hours in a Fisher Isotemp Model 281A oven at a temperature of $85^{\circ} \mathrm{C}$. Optimum drying times were determined by observing sample weight as a function of dry time for a typical sample. Dried samples were ground in a mortar and pestle and collected in small vials. Samples weights were set to $250 \mathrm{mg}$ net. INAA (instrumental neutron activation analysis) was used to analyze each sample using the facilities of the Rhode Island Nuclear Science Center. Irradiation times were optimized for adequate counting statistics, sample size and neutron flux. Samples were pneumatically delivered to the core, where the neutron flux was about $4 \times 10^{12} \mathrm{n} / \mathrm{cm}^{2} / \mathrm{sec}$, and irradiated for 12 seconds. Actual irradiation flux was monitored using a small Aluminum chad in each sample container. In addition, separate samples of Buffalo River standard sediment was used for concentration calibration purposes. The literature well documents this procedure [7]. This procedure allowed for the analysis of the following short lived isotopes: $\mathrm{Al}^{28}, \mathrm{Mg}^{27}, \mathrm{Ti}^{51}, \mathrm{Va}^{52}, \mathrm{Na}^{24}, \mathrm{CL}^{38}, \mathrm{Mn}^{56}, \mathrm{~K}^{42}$, $\mathrm{Ba}^{139}$, and $\mathrm{Dy}^{165}$. (Longer lived isotope analysis including several heavy metals are part of another study currently under way.)

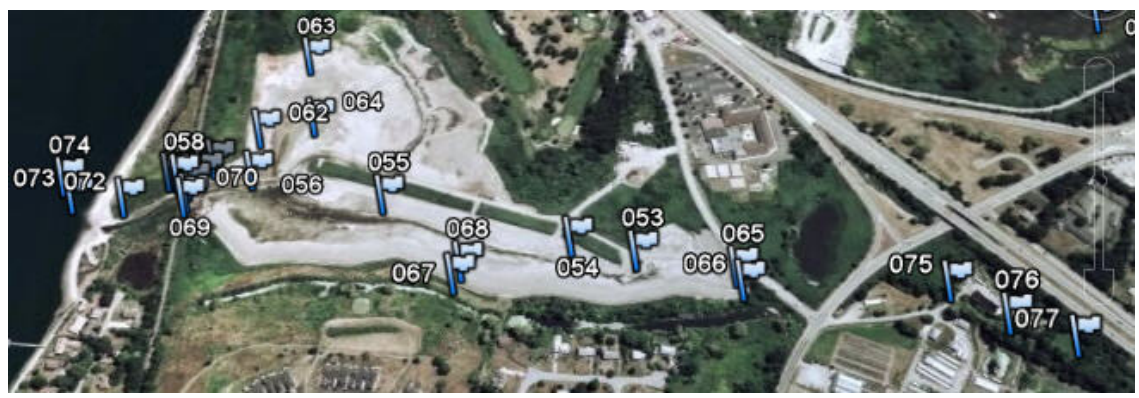

Figure 7: $\quad$ Sediment sampling locations. 


\section{Results and discussion}

Table 1 shows the results of sample analysis using the aforementioned INAA technique. Errors in these data, arising from integrated peak count rates, uncertainties in calibration standards and flux monitoring are dominated by the count rates. The ranges of percent errors are summarized in Table 2.

Table 1: $\quad$ Results of INAA on short lived isotopes.

\begin{tabular}{|c|c|c|c|c|c|c|c|c|c|c|c|c|}
\hline $\begin{array}{c}\text { Way } \\
\text { Point \# }\end{array}$ & Al 28 & Mg 27 & Ti 51 & Va 52 & $\mathrm{Na} 24$ & $\mathrm{Cl} 38$ & Mn 56 & K 42 & Ba 139 & Dy 165 & Salinity & Depth \\
\hline & $\%$ & $\%$ & $\%$ & PPM & $\%$ & $\%$ & PPM & $\%$ & PPM & PPM & PPT & $\mathrm{cm}$ \\
\hline 52 & 5.38 & 0.73 & 0.372 & 65 & 1.710 & 0.529 & 404 & 2.43 & 315 & 6 & 28 & 75 \\
\hline 53 & 6.83 & 1.15 & 0.434 & 83 & 2.096 & 0.876 & 524 & 3.02 & 497 & 8 & 28 & 135 \\
\hline 54 & 6.12 & 0.91 & 0.392 & 77 & 1.936 & 0.793 & 443 & 2.26 & 337 & 8 & 28 & 112.5 \\
\hline 55 & 6.39 & 1.01 & 0.369 & 81 & 1.903 & 0.713 & 450 & 2.91 & 418 & 8 & 30 & 140 \\
\hline 56 & 5.79 & 1.03 & 0.322 & 74 & 2.055 & 1.070 & 446 & 2.34 & 297 & 6 & 29 & 135 \\
\hline 57 & 6.18 & 0.88 & 0.455 & 72 & 1.991 & 0.728 & 470 & 2.71 & 406 & 7 & 29 & 165 \\
\hline 62 & 4.47 & 0.87 & 0.740 & 84 & 2.843 & 2.360 & 315 & 1.59 & 342 & 4 & 30 & 85 \\
\hline 63 & 6.36 & 0.99 & 0.407 & 79 & 1.963 & 0.766 & 410 & 2.80 & 416 & 7 & 27 & 30 \\
\hline 64 & 6.18 & 1.11 & 0.383 & 77 & 1.859 & 0.729 & 427 & 2.67 & 404 & 7 & 27 & 57 \\
\hline 59 & 7.06 & 1.13 & 0.358 & 76 & 2.066 & 0.800 & 409 & 2.76 & 529 & 9 & 30.5 & 80 \\
\hline 58 & 5.43 & 0.84 & 0.755 & 66 & 1.957 & 1.060 & 310 & 2.24 & 342 & 6 & 30 & 115 \\
\hline 61 & 5.35 & 0.89 & 0.798 & 65 & 0.390 & 0.034 & 1275 & 1.42 & 419 & 4 & 23 & 70 \\
\hline 71 & 3.38 & 0.00 & 0.536 & 31 & 1.263 & 0.311 & 260 & 1.73 & 337 & 3 & 30 & 110 \\
\hline 72 & 5.88 & 1.35 & 0.364 & 78 & 2.066 & 1.09 & 470 & 2.91 & 441 & 6 & 30.5 & 72 \\
\hline 73 & 2.94 & 0.00 & 0.389 & 33 & 1.020 & 0.301 & 323 & 1.18 & 281 & 2 & 31 & 73 \\
\hline 74 & 3.56 & 0.00 & 0.572 & 36 & 1.220 & 0.325 & 359 & 1.61 & 356 & 3 & 30 & 74 \\
\hline 77 & 3.76 & 0.00 & 0.340 & 33 & 1.060 & 0.0108 & 902 & 1.54 & 339 & 3 & 2 & 77 \\
\hline 76 & 3.46 & 0.00 & 0.535 & 37 & 0.780 & 0.00720 & 538 & 1.67 & 348 & 3 & 2 & 76 \\
\hline 75 & 3.52 & 0.00 & 0.916 & 47 & 0.870 & 0.00960 & 1194 & 1.67 & 281 & 3 & 1.5 & 75 \\
\hline 66 & 6.71 & 0.00 & 0.183 & 64 & 0.419 & 0.0369 & 1369 & 1.52 & 450 & 5 & & 35 \\
\hline 67 & 1.05 & 0.00 & 0.098 & 10 & 1.008 & 0.0155 & 514 & 1.82 & 314 & 4 & & 30 \\
\hline 68 & 6.17 & 1.04 & 0.381 & 79 & 1.265 & 0.0958 & 444 & 2.87 & 408 & 8 & 5 & 30 \\
\hline 69 & 5.46 & 0.00 & 0.380 & 63 & 1.189 & 0.0098 & 489 & 2.64 & 480 & 6 & 3 & 20 \\
\hline 70 & 6.39 & 0.00 & 0.322 & 81 & 0.773 & 0.0273 & 783 & 2.19 & 459 & 2 & 3 & 30 \\
\hline
\end{tabular}

Table 2: $\quad$ Error ranges for concentration results.

\begin{tabular}{|c|c|c|c|c|c|c|c|c|c|}
\hline Al 28 & Mg 27 & Ti 51 & V 52 & Na 24 & Cl 38 & Mn 56 & K 42 & Ba 139 & Dy 165 \\
\hline$\sim 23 \%$ & $4 \%$ & $5 \%-7 \%$ & $7 \%-8 \%$ & $\sim 5 \%$ & $15 \%-29 \%$ & $4 \%$ & $11 \%-14 \%$ & $36 \%-38 \%$ & $9 \%-17 \%$ \\
\hline
\end{tabular}




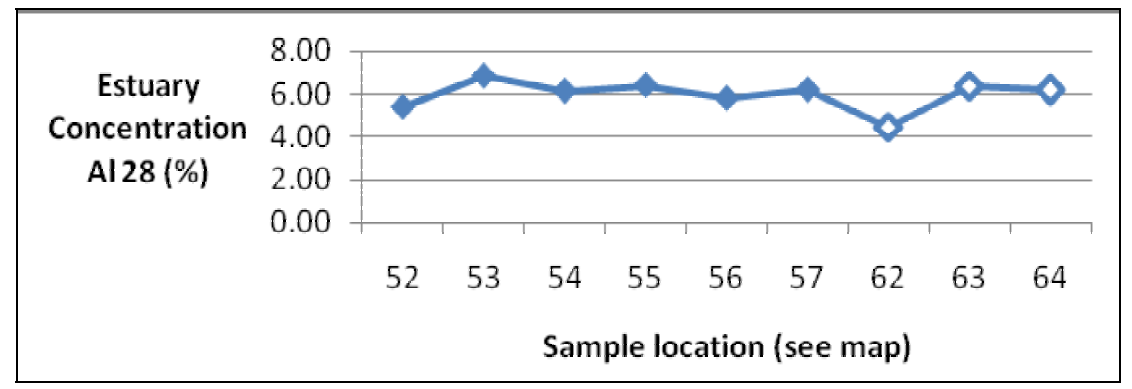

(a)

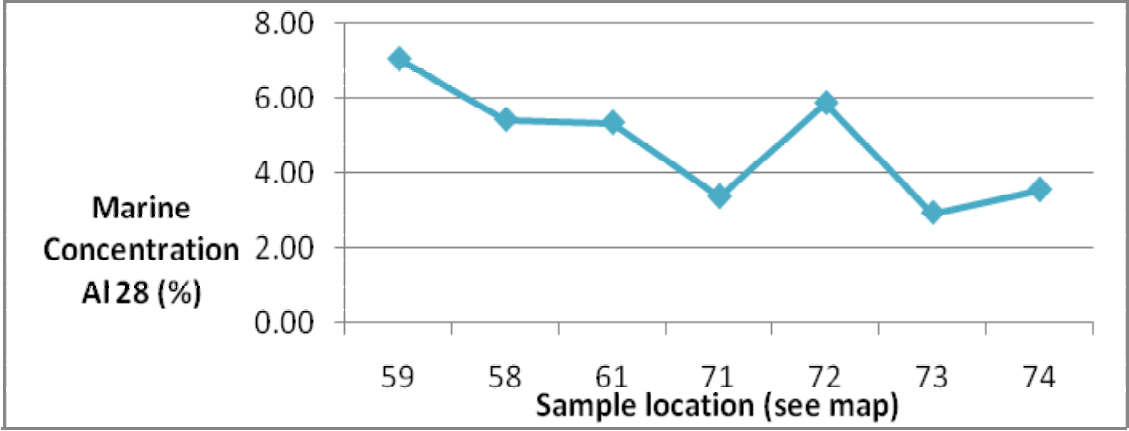

(b)

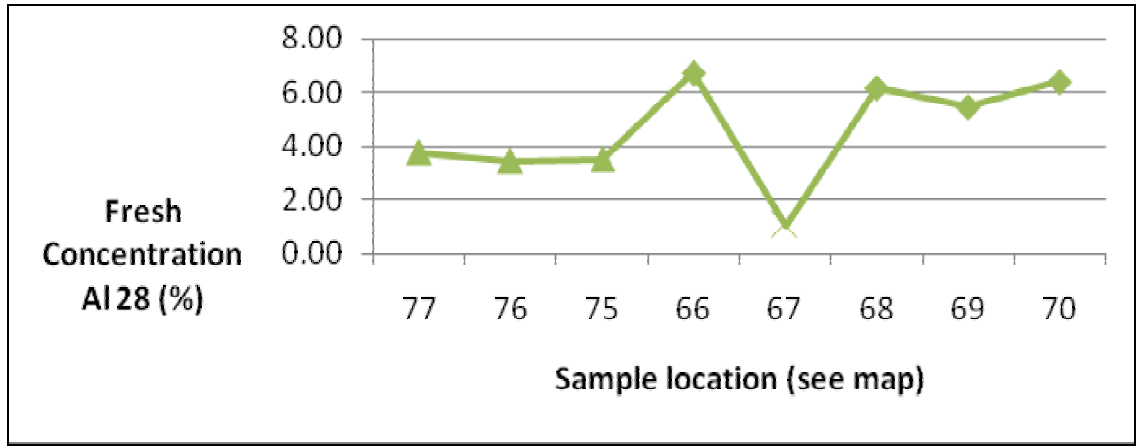

(c)

Figure 8: Al-28 Concentration in the (a) Estuary- (b) Marine- and (c) FreshWater segments of the Town Pond system.

Samples 52 through 57 are from the west segment of the estuary and 62 through 64 from the west segment. Samples 58, 59, 61, and 71 through 74 are from the marine segment and the balance from the fresh water segment. In order to make sense of much of this data, one must consider the restoration process, which involved the removal of an estimated 125,000 cubic yards of dredge spoils and the replacement with fill soils to create the plan shown in Figure 4. To illustrate the point consider the most abundant isotope in the survey, i.e. $\mathrm{Al}^{28}$. Figures 8(a), (b) and (c) show the measured concentration of $\mathrm{Al}^{28}$ at sample 
locations in the estuary-, marine- and fresh- water segments of the system respectively. Notice in Figure 8(c) the excursions in the Al concentrations. Samples 67 and 68 were taken from just west of the berm and a bit further west respectively in the same general location. The latter was beyond a space that contained dense shrubs, clearly not touched during the restoration and the former in an excavated area. The data supports the hypothesis that sample 68 , with an $\mathrm{Al}^{28}$ concentration of $6.17 \pm 1.4 \%$, was part of the restoration excavation and sample 67 , with a concentration of $1.05 \pm .24 \%$, was not. Indeed the average concentration in the estuary (Figure 8(a)), which was fully part of the excavation and fill process is $6.0 \pm 1.4 \%$ similar to the data of samples 66 and 68 through 70 , all of which were part of the excavation and re-routing of the fresh water leading to the flap gate. Sample 67 was clearly within the fresh water flow (or overflow) area and 68 showed signs of water draining from the berm or from high water flows from Founder's Brook. Notice that the first three points, 75 through 77, in Figure 8(c) represent samples taken far upstream near the head of Founder's Brook, clearly having a different sediment with average $\mathrm{Al}^{28}$ concentration of $3.6 \pm 0.8 \%$. While this distinction between segments is noticeable, there are anomalies in isolated samples perhaps due to the mixing of soils including remnant traces of dredge spoils with trucked in fill and longstanding local soils. Multiple samples from each location would help sort out these few excursions in the data.

\section{Conclusion}

Town Pond offers a unique opportunity to observe the early evolution of a new estuarian ecosystem and provides a natural laboratory for short and long-term studies of the dynamics of small estuaries. This opportunity arises from the newness of the system, the scale and arrangement of the estuary and the rather constrained entry point of fresh water inflow. The present work begins a series of planned experiments that taken together will offer a baseline for modelling the dynamics of the estuary while tracing its actual and potential evolution.

\section{Acknowledgements}

Padhraic Mulligan is acknowledged for his efforts supporting this study while he was a student in the Systems Dynamics Research Group in the Department of Engineering-Physics-Systems at Providence College. We would also like to thank David Larsen of the Army Corps of Engineers for providing the construction details of the site. Finally, Thurston Gray, mentioned earlier in the paper, is acknowledged for providing the authors access to hindsight prerestoration data and for continuing to obtain basic data following the restoration. These are expected to be valuable in the water balance and dynamics studies currently underway in our laboratory. 


\section{References}

[1] University of New Hampshire Library Digital Collections Initiative

[2] State, Federal and Local officials mark completion of \$4.6 million Town Pond environmental restoration project in Portsmouth, RI Department of Environmental Management News Release, June 16, 2008.

[3] Mecca, S.J., Severino, C. \& Barber, R.W., Pollution flushing models in Stella, Development and Application of Computer Techniques to Environmental Studies X, edited by G. Latini, G. Passerini and C.A. Brebbia, pp. 125-134, WIT Press: Southampton, UK, 2004.

[4] Mecca, S.J., Severino, C. \& Barber, R.W., Pollution flushing in cascading tidal basins, WIT Transactions on The Built Environment, 78, pp. 93-100, edited by M. da Conçeicao Cunha and C.A. Brebbia, WIT Press: Southampton, UK, 2005.

[5] Mecca, S.J., Barber, R.W. \& Tombarello, J., Alternative loading functions in the MSB pollution flushing model, WIT Transactions on Ecology and the Environment, 88, pp. 89-97, edited by C.A. Brebbia, WIT Press: Southampton, UK, 2006.

[6] Mecca, S.J., Barber, R.W., Mellor, G. \& Walsh, G., Application of the SB pollution-flushing model to Great Salt Pond on Block Island, WIT Transactions on Ecology and the Environment, 104, pp. 189-197, edited by C.A. Brebbia and K.L. Katsifarakis, WIT Press: Southampton, UK, 2007.

[7] R. Sinem Atgin et al, Investigation of the sediment pollution in Izmir Bay: trace elements, Spectrochimica Acta Part B 55, pp.1151-1164, 2000. 